\title{
COVID-19 and tuberculosis co-infection: a neglected paradigm
}

\author{
Arkapal Bandyopadhyay', Sarika Palepu ${ }^{2}$, Krishna Bandyopadhyay ${ }^{3}$, Shailendra Handu ${ }^{1}$ \\ ${ }^{1}$ Department of Pharmacology, All India Institute of Medical Sciences, Rishikesh; ${ }^{2}$ Department of Community \\ Medicine, VCSGGMS\&RI, Srinagar, Uttarakhand; ${ }^{3}$ Saint Teresa Kolkata Memorial TB Hospital, Kolkata, India
}

\begin{abstract}
COVID-19 pandemic has posed a serious threat to global healthcare and economy. India has one of the highest burden of COVID-19 disease in the world. Presentation of the disease is highly variable. Tuberculosis, one of the top ten causes of mortality has a presentation conspicuously similar to the current SARSCoV-2 infection. Co-infections of Tuberculosis with past corona virus epidemics like SARS and MERS-CoV had posed a major threat in spread of the disease. We suggest proper tuberculosis screening, isolation of patient, remote tracking of suspected patients for symptoms during the current pandemic.
\end{abstract}

\section{Introduction}

COVID-19 has been declared a Public Health Emergency of International Concern on $30^{\text {th }}$ of January, 2020 by World Health

Correspondence: Sarika Palepu, Department of Community Medicine, Medical College Campus, VCSGGMS\&RI, Srinagar, Uttarakhand, India. Tel. 091-7980975904.

E-mail: sarikapalepu@gmail.com

Key words: COVID-19; tuberculosis; coinfection; India.

Contributions: All the authors made a substantive intellectual contribution, performed part of the experiments. All the authors have read and approved the final version of the manuscript and agreed to be accountable for all aspects of the work.

Conflict of interest: The authors declared no potential conflicts of interest.

Funding: None.

Patient consent for publication: Not applicable.

Availability of data and materials: Not applicable.

Received for publication: 8 June 2020.

Accepted for publication: 7 July 2020.

${ }^{\circ}$ Copyright: the Author(s), 2020

Licensee PAGEPress, Italy

Monaldi Archives for Chest Disease 2020; 90:1437

doi: $10.4081 /$ monaldi.2020.1437

This article is distributed under the terms of the Creative Commons Attribution Noncommercial License (by-nc 4.0) which permits any noncommercial use, distribution, and reproduction in any medium, provided the original author(s) and source are credited.
Organisation (WHO) [1]. The presentation of disease ranges from a mild cough, fever and sore throat to pneumonia, acute respiratory distress syndrome and death. Patients with associated comorbidities are usually more vulnerable for a severe disease. As of $15^{\text {th }}$ June 2020,78 million people have been infected in 216 countries with case fatality rate of $5.52 \%$. India has reported 13.7 million cases with 9520 deaths during the same time [2].

Tuberculosis (TB) is a chronic persistent bacterial disease with a high burden in developing countries like India. TB is of high concern during this pandemic as it presents with symptoms similar to COVID-19. WHO estimates that every year, around 10 million people fall sick with TB infection. It is one of the the top ten causes of mortality globally. The disease manifests mostly in adults with male:female ratio of $2: 1$. It is estimated that worldwide, 1.7 billion people are infected with Mycobacterium tuberculosis and are hence at risk of developing the disease. In 2018, most TB cases were in the WHO regions of South-East Asia (44\%), Africa (24\%) and Western Pacific (18\%), with smaller shares in Eastern Mediterranean (8\%), Americas (3\%) and Europe (3\%) [3].

In this review, we strive to provide evidence from published literature regarding coronavirus related infections (SARS and MERS-CoV) and inapparent/sub-clinical TB co-infection and formulate measures to prevent this global dual burden.

\section{Lessons from SARS and MERS-CoV}

It is a well-established fact that corona viruses have caused global concerns in the past with Severe Acute Respiratory Syndrome (SARS) in 2002 and Middle East Respiratory Syndrome (MERS-CoV) in 2013. Genetic composition of the SARS-CoV-2 is very similar to SARS-CoV according to a study [4]. Hence, we have conducted a search with keywords SARS, Tuberculosis and MERS-CoV. Few case studies assessing the risk and burden of co-infection with TB were retrieved using the search engine.

In 2003, a healthcare worker (HCW) in Taipei, Taiwan, was screened for SARS symptoms. He was found to have pleural effusion and later tested positive for TB. In the same hospital, a total of 60 cases of TB among HCWs were diagnosed indicating nosocomial transmission [5]. Two patients amongst 236 probable SARS cases in Singapore presented with persistent respiratory symptoms and/or worsening chest radiography findings. They were later found to be co-infected with pulmonary TB. As infection with SARS coronavirus causes a temporary suppression of cellular immunity, these patients were predisposed to aggravated reactivation or new infection with TB [6]. In Beijing, it was seen that 3 patients were co-infected with TB and SARS. Two of them were known cases of TB and had contracted SARS as they shared 
same hospital ward surroundings. One of the patients developed TB after being cured for SARS, which might again be a result of sharing same surroundings with TB patients [7]. In China, another case was reported where a young girl suffering from pulmonary TB was falsely diagnosed as SARS. The patient later on developed SARS as she was isolated with other SARS patients. The treatment of SARS and TB resulted in liver dysfunction. Although the patient recovered uneventfully, it imposes the risk of mis-diagnosis and burden on the patient [8].

Similarly, in Riyadh, 2 cases of TB co-infection were reported from patients of MERS-CoV. Both of them had long-lasting symptoms which predict their chances of being infected with TB prior and with MERS-CoV later. This study highlighted the importance of detailed evaluation of suspected MERS-CoV patients for the presence of other infectious diseases, such as TB and avoid nosocomial transmission in turn [9].

\section{Cellular responses - greater symptomatic dilemma?}

Patients diagnosed with TB can become infected with COVID-19, which in turn might result in deterioration of a patient's condition. According to the Center for Disease Control and Prevention, TB patients who are at least 65 years old, have respiratory compromise from their TB infection or other medical conditions, including HIV and immunocompromised state, are at greater risk for severe COVID-19 infection [10]. A study has evaluated the host-expression correlation with SARS-CoV-2 and interaction of 26 proteins of SARS-CoV-2 with 332 human proteins. It was seen that Mycobacterium tuberculosis shares most host protein interaction partners (same interactome) as SARSCoV-2 and is of utmost importance as both infections have high affinity towards lung tissue [11].

Past experiences with SARS and MERS-CoV have shown that adverse effects of TB occurred during and after the infectious phase. Number of patients with COVID-19 being much greater than SARS and MERS-CoV, risk of co-infection with TB might be anticipated to be in much higher proportions. We urge that it's high time to assess the burden of TB in this pandemic, preventing longterm suffering of mankind.

\section{Evidence in recent times - COVID 19 and TB co-infection}

Very few studies have determined the mortality in cases of co-infection with COVID-19 and TB. A study was done by Tadolini et al. in a cohort of 49 patients. It was seen that $53.0 \%$ patients had past history of TB, 28.5\% developed COVID-19 first and $18.3 \%$ patients were diagnosed with TB and COVID-19 simultaneously. In $38.8 \%$ patients, COVID-19 developed during treatment for TB showcasing the potential risk of transmission to care-givers. Lack of/inadequate protective measures in handling patients of TB favoured the nosocomial spread of COVID-19 in two health care workers [12]. Another study done by Chen et al. warranted that COVID-19 infection and severity would be likely higher in patients of active and latent TB infection [13]. In a study by Motta et al. in Italy, two cohorts of patients co-infected with TB and COVID-19 were analysed. In about 69 patients from two cohorts, 8 patients $(11.6 \%)$ succumbed to the co-infection. It was seen that in majority of the patients, SARS-COV-2 infection was nosocomial further strengthening the need for strict infection prevention and control (IPC) practices to prevent cross-infection. COVID-19 co infection in TB patients was found to accelerate the disease course leading to death in few of them. However, prognosis of co-infection in long term was not assessed in this study [14]. Though these studies showed preliminary manifestations, association of TB and COVID-19 cannot be ruled out and hence appropriate precautions and preparation of the health system to tackle the impending burden of co-infection is the need of the hour. We hereby present the similarities and differences in TB and COVID-19 in Table 1.

\section{Infection prevention and control practices - growing concern for communicable diseases}

A review by Migliori et al. [31] reinforced the vital need for IPC practices at the level of patients, family members, health care personnel and hospital surroundings to prevent the communicability of tuberculosis infection. As the main mode of spread is through droplets, IPC plays a predominant role to curb the spread of tuberculosis. Administrative control in proper segregation of high-risk patients and minimising risk of exposure, environmental control in the form of adequate mechanical and natural ventilation and provision of personal protective equipment to health care workers constitute the mainstay of IPC. Even in COVID-19, WHO has advocated to follow similar IPC practices and spatial distancing of atleast 1 metre between two suspected patients [32].

\section{Action points-need for focus}

Following are few measures which could be followed in practice to overcome the dual burden of TB and COVID-19:

i) Immunity to $\mathrm{TB}$ in developing countries might be the leading reason of less cases of COVID-19. Although, demographic profile, number of samples tested and socio-demographic determinants might be a serious factor of concern, this needs to be explored further.

ii) Few measures can be taken in the ongoing pandemic to improve effective screening of patients for TB. History of the patient regarding duration of symptoms and past history or family history of active TB can be taken to categorise potential suspects for TB and provide remedial measures as needed.

iii) Patients who seem to be strong suspects (with classical symptoms of TB) ought to be tested for corona virus and mycobacterium tuberculosis to avoid unforeseen burden in the coming times.

iv) Practices like segregation of cases if symptomatic for TB have to be followed without fail to avoid spread to other suspected patients of COVID-19.

v) Cohorting of patients co-infected with COVID-19 and TB has to be done with utmost care in isolation wards to protect patients of COVID-19 from contracting TB as was seen in the past with SARS and MERS-CoV infections.

vi) Newly registered patients of TB should be tested for corona virus to avoid potential mis-diagnosis. 
vii) Follow-up of cured/discharged patients of COVID-19 infection should be done through mobile messages to check for residual respiratory symptoms if any and need for evaluation of Mycobacterium tuberculosis. viii) Developing countries of SEAR and Africa regions of WHO contribute to majority of the TB burden globally. Acting diligently at this hour can save from unforeseen burden of co-infection of TB and COVID-19, if any in the future in these areas.

Table 1. Similarities and differences between tuberculosis and COVID-19.

\begin{tabular}{|c|c|c|c|}
\hline No & Characteristic & Tuberculosis & COVID-19 \\
\hline 1 & Geographical distribution & $\begin{array}{l}\text { Global existence } \\
\text { More prevalence in South-East Asia region and African region [3] }\end{array}$ & More incidence in Americas and Europe [2] \\
\hline 2 & Incidence & 10 million cases (in 2018) [3] & 10 million cases and counting [2] \\
\hline 3 & Agent & $\begin{array}{l}\text { Mycobacterium tuberculosis } \\
\text { Corona virus shares genomic similarities with Mycobacterium tub }\end{array}$ & $\begin{array}{l}\text { Novel Coronavirus (SARS COV-2) } \\
\text { erculosis [4] }\end{array}$ \\
\hline 4 & Age group & $\begin{array}{l}\text { All age groups and both sexes are at risk } \\
\text { Mostly affects adults in productive age group (15-34 years). } \\
\text { People with HIV/AIDS are at higher risk of infection [3] }\end{array}$ & $\begin{array}{l}\text { Older adults and people who have severe underlying } \\
\text { medical conditions like heart or lung disease or } \\
\text { diabetes seem to be at higher risk for developing } \\
\text { more serious complications from COVID-19 illness } \\
\text { [15] }\end{array}$ \\
\hline 5 & Incubation period & Variable, symptoms develop weeks to years after exposure [16] & $2-14$ days $[17]$ \\
\hline 6 & Mode of spread & $\begin{array}{l}\text { Respiratory droplets produced when an infected person coughs, } \mathrm{s} \\
\text { - }\end{array}$ & $\begin{array}{l}\text { Virus can also spread from touching a surface or } \\
\text { object that has virus on it and then touching their } \\
\text { own mouth, nose, or possibly their eyes (less } \\
\text { common route) [19] }\end{array}$ \\
\hline 7 & Clinical features & $\begin{array}{l}\text { Cough with sputum and blood at times, weight loss, fever and } \\
\text { night sweats, chest pain, weakness [20] }\end{array}$ & $\begin{array}{l}\text { Fever or chills, cough, shortness of breath or } \\
\text { difficulty breathing, fatigue, muscle or body aches, } \\
\text { headache, new loss of taste or smell, sore throat, } \\
\text { congestion or runny nose, nausea or vomiting, } \\
\text { diarrhoea [17] }\end{array}$ \\
\hline 8 & Laboratory features & $\begin{array}{l}\text { High erythrocyte sedimentation rate, leukopenia, lymphopenia, hig } \\
\text { thrombocytopenia, anemia [21] }\end{array}$ & $\begin{array}{l}\text { hh lactate dehydrogenase }[21,22,23] \\
\text { Decreased albumin, high C-reactive protein, high } \\
\text { aspartate amino transferase, high alanine amino } \\
\text { transferase, high creatinine kinase, leukocytosis, } \\
\text { high bilirubin, high creatinine [23] }\end{array}$ \\
\hline 9 & Chest X-ray features & $\begin{array}{l}\text { Consolidation, thick walled cavity, cavities with air-fluid levels, } \\
\text { clustered and military nodules and pleural effusion [24] }\end{array}$ & $\begin{array}{l}\text { Bilateral lower lobe consolidations, peripheral air } \\
\text { space opacities, ground glass opacities, diffuse } \\
\text { lung opacities and pleural effusion [25] }\end{array}$ \\
\hline 10 & Diagnostic tests & $\begin{array}{l}\text { Sputum smear microscopy, culture test, TB interferon gamma } \\
\text { release assays, chest X-rays, serological tests, tuberculin skin } \\
\text { tests, molecular assays as Genexpert and Truenat [26] }\end{array}$ & $\begin{array}{l}\text { Viral load detection (RT-PCR), serological-antibody } \\
\text { tests (IgM and IgG) [27]TrueNat Beta CoV is used } \\
\text { as a screening tool in India [28] }\end{array}$ \\
\hline 11 & Treatment & $\begin{array}{l}\text { Specific treatment guidelines available (isoniazid, rifampicin, } \\
\text { ethambutol, pyrazinamide, streptomycin, etc.) }\end{array}$ & $\begin{array}{l}\text { Many trials are underway. Hydroxychloroquine and } \\
\text { corticosteroids are currently in place }\end{array}$ \\
\hline 12 & Case fatality & 1.4 million deaths (in 2018) [3] & $\begin{array}{l}0.5 \text { million deaths and counting (case fatality rate is } \\
4.9 \% \text { ) [2] }\end{array}$ \\
\hline 14 & Health sector expenditure & USD 6.8 billion (in 2018) [3] & $\begin{array}{l}\text { Unknown, but would be huge leading to global } \\
\text { recession }\end{array}$ \\
\hline 15 & Social impact - stigma & Yes [29] & \\
\hline 16 & Data sharing platform & Lack of organised data sharing platform [29] & \\
\hline 17 & $\begin{array}{l}\text { International surveillance } \\
\text { system }\end{array}$ & Lack of finances [29] & $\begin{array}{l}\text { Appropriate surveillance systems in place to track } \\
\text { the spread [29] }\end{array}$ \\
\hline 18 & $\begin{array}{l}\text { Knowledge on individual } \\
\text { susceptibility }\end{array}$ & Absent [29] & \\
\hline 19 & Vaccine availability & BCG $[30]$ & $\begin{array}{l}\text { Currently not available. Research for new vaccine } \\
\text { is ongoing [30] }\end{array}$ \\
\hline 20 & Rapid policy response & No [30] & Yes $[30]$ \\
\hline 21 & Contact tracing & Helpful in case detection [30] & \\
\hline 22 & Preventive measures & Following respiratory hygiene and cough eti & iquettes [30] \\
\hline
\end{tabular}




\section{Conclusions}

This review provides an insight into the neglected paradigm of a long-standing infectious disease, tuberculosis amidst the ongoing COVID-19 pandemic. Though multi-faceted approaches are in place to deal with the pandemic, few other measures taken at this time might enhance to contain COVID-19 and prevent the illeffects of missing potential suspects of Tuberculosis.

\section{References}

1. World Health Organization. Coronavirus disease (COVID-19) Pandemic - Emergency Use Listing Procedure (EUL) open for in vitro diagnostics. Geneva: World Health Organization. Available from: https:/www.who.int/diagnostics_laboratory/ EUL/en/. Accessed: 15 th June, 2020.

2. World Health Organization. Coronavirus Disease (COVID-19) Dashboard. Geneva: World Health Organization. Available from: https://covid19.who.int/. Accessed: $15^{\text {th }}$ June, 2020.

3. World Health Organisation. Global Tuberculosis Report 2019. Geneva: World Health Organization. Available from: https://apps.who.int/iris/bitstream/handle/10665/329368/9789 241565714-eng.pdf?ua=1. Accessed: $27^{\text {th }}$ of May, 2020.

4. Chan JF, Kok KH, Zhu Z, et al. Genomic characterization of the 2019 novel human-pathogenic coronavirus isolated from a patient with atypical pneumonia after visiting Wuhan. Emerg Microbes Infect 2020;9:221-36. doi:10.1080/22221751.2020. 1719902

5. Centers for Disease Control and Prevention. Nosocomial Transmission of Mycobacterium tuberculosis Found Through Screening for Severe Acute Respiratory Syndrome- Taipei, Taiwan, 2003. Available from: https:/www.cdc.gov/mmwr/ preview/mmwrhtml/mm5315a5.htm. MMWR weekly, 2004; 53:321-2.

6. Low JGH, Lee CC, Leo YS, et al. Severe Acute Respiratory Syndrome and Pulmonary Tuberculosis. Clin Infect Dis 2004;38:e123-e125.

7. Liu W, Fontanet A, Zhang PH, et al. Pulmonary tuberculosis and SARS, China. Emerg Infect Dis 2006;12:707-9.

8. Wong CY, Wong KY, Law TS, et al. Tuberculosis in a SARS outbreak. J Chin Med Assoc 2004;67:579-82.

9. Alfaraj SH, Al-Tawfiq JA, Altuwaijri TA, Memish ZA. Middle East Respiratory Syndrome Coronavirus and Pulmonary Tuberculosis Coinfection: Implications for Infection Control. Intervirology. 2017;60:53-5.

10. Centers for Disease Control and Prevention. Tuberculosis and Public Health Emergencies. Available at https://www.cdc. gov/tb/education/public-health-emergencies.htm. Atlanta: Centers for Disease Control and Prevention. Accessed: $27^{\text {th }}$ of April, 2020.

11. Gordon DE, Jang GM, Bouhaddou M, et al. A SARS-CoV-2 protein interaction map reveals targets for drug repurposing. Nature. 2020;10.1038/s41586-020-2286-9. doi:10.1038/s41586-020-2286-9.

12. Tadolini M, Codecasa LR, García-García JM, et al. Active tuberculosis, sequelae and COVID-19 co-infection: first cohort of 49 cases. Eur Resp J 2020;2001398. doi: 10.1183/ 13993003.01398-2020

13. Chen Y, Wang Y, Fleming J, et al. Active or latent tuberculosis increases susceptibility to COVID-19 and disease severity.
MedRxiv 2020. Available from: www.medrxiv.org/content/10.1101/2020.03.10.20033795v1.full.pdf. Accessed: July $1,2020$.

14. Motta I, Centis R, D'Ambrosio L, et al. Tuberculosis, COVID19 and migrants: preliminary analysis of deaths occurring in 69 patients from two cohorts. Pulmonology 2020;26:233-40

15. Centers for Disease Control and Prevention. Older adultsCoronavirus disease (COVID-19). Atlanta: Centers for Disease Control and Prevention. Available from: https://www. cdc.gov/coronavirus/2019-ncov/need-extra-precautions/olderadults.html. Accessed on 3 July, 2020.

16. Centers for Disease Control and Prevention. Exposure to TB. Available from: https://www.cdc.gov/tb/topic/basics/exposed. htm. Atlanta: Centers for Disease Control and Prevention. Accessed: 3 July, 2020.

17. Centers for Disease Control and Prevention. Symptoms of Coronavirus. Available from: https:/www.cdc.gov/coronavirus/2019-ncov/symptoms-testing/symptoms.html. Atlanta: Centers for Disease Control and Prevention. Accessed: 2 July, 2020.

18. Centers for Disease Control and Prevention. How TB spreads? Atlanta: Centers for Disease Control and Prevention. Available from: https://www.cdc.gov/tb/topic/basics/howtbspreads.htm. Accessed: 2 July, 2020.

19. Centers for Disease Control and Prevention. How COVID-19 spreads? Atlanta: Centers for Disease Control and Prevention. Available at https://www.cdc.gov/coronavirus/2019-ncov/prevent-getting-sick/how-covid-spreads.html. Accessed: 2 July, 2020.

20. Centers for Disease Control and Prevention. Tuberculosis. Atlanta: Centers for Disease Control and Prevention. Available at https://www.who.int/news-room/fact-sheets/detail/tuberculosis. Accessed: 3 July, 2020.

21. Abay F, Yalew A, Shibabaw A, Enawgaw B. Hematological Abnormalities of Pulmonary Tuberculosis Patients with and without HIV at the University of Gondar Hospital, Northwest Ethiopia: A Comparative Cross-Sectional Study. Tuberc Res Treat 2018;2018:5740951.

22. Sharma PR, Jain S, Bamezai RN, Tiwari PK. Utility of serum $\mathrm{LDH}$ isoforms in the assessment of mycobacterium tuberculosis induced pathology in TB patients of Sahariya tribe. Indian J Clin Biochem 2010;25:57-63.

23. Rodriguez-Morales AJ, Cardona-Ospina JA, GutiérrezOcampo E, et al. Clinical, laboratory and imaging features of COVID-19: A systematic review and meta-analysis. Travel Med Infect Dis 2020;34:101623.

24. Bhalla AS, Goyal A, Guleria R, Gupta AK. Chest tuberculosis: Radiological review and imaging recommendations. Indian $\mathrm{J}$ Radiol Imaging 2015;25:213-25.

25. Jacobi A, Chung M, Bernheim A, Eber C. Portable chest X-ray in coronavirus disease-19 (COVID-19): A pictorial review. Clin Imaging 2020;64:35-42.

26. TBFACTS.ORG. Tests for TB - Sputum microscopy, skin test, IGRAs. Available from: https://tbfacts.org/tests-tb/. Accessed: 3 July, 2020.

27. Centers for Disease Control and Prevention. Corona virus disease (COVID-19). Atlanta: Centers for Disease Control and Prevention. Available from: https://www.cdc.gov/coronavirus/2019-ncov/testing/index.html. Accessed: 3 July, 2020.

28. Indian Council Of Medical Research, Department Of Health Research. Guidance on the use of TruenatTM beta CoV. Available from: https:/www.icmr.gov.in/pdf/covid/labs/ Guidance_TrueNat_14042020.pdf. Accessed: 3 July, 2020. 
29. Alagna R, Besozzi G, Codecasa LR, et al. Celebrating World Tuberculosis Day at the time of COVID-19. Eur Respir J 2020;55:2000650.

30. Dara M, Sotgiu G, Reichler MR, et al. New diseases and old threats: lessons from tuberculosis for the COVID-19 response. Int J Tuberc Lung Dis 2020;24:544-45.

31. Migliori GB, Nardell E, Yedilbayev A, et al. Reducing tuberculosis transmission: a consensus document from the World
Health Organization Regional Office for Europe. Eur Respir J 2019;53:1900391.

32. World Health Organisation. Infection prevention and control during health care when novel coronavirus ( $\mathrm{nCoV}$ ) infection is suspected. Geneva: World Health Organisation. Available from: https://apps.who.int/iris/bitstream/handle/10665/332447/WHO2019-nCoV-IPC-2020.1-eng.pdf. Accessed: 3 July, 2020. 